\title{
Correction to: What shapes cognitions of climate change in Europe? Ideology, morality, and the role of educational attainment
}

\author{
Heinz Welsch ${ }^{1}$ \\ Published online: 8 March 2022 \\ (c) AESS 2022
}

\section{Correction to: Journal of Environmental Studies and Sciences}

https://doi.org/10.1007/s13412-021-00745-7

The original version of this article unfortunately contained a mistake. The Introduction should read:

\section{Introduction}

Cognitions about climate change are highly relevant for climate change mitigation for at least two reasons (Gifford 2011): First, people unaware of or skeptic about the existence, origins and impacts of climate change are unlikely to take measures to curb greenhouse gas emissions or support public policies to protect the climate. Second, even among those who are aware of the problem, a lack of knowledge about the cause and extent of climate change may lead to ignorance about which (individual and collective) actions are available and how effective different actions are. Sound knowledge about climate change and the options for ameliorating is thus an important precondition for effective climate policy.

Action-relevant cognitions about climate change are shaped by several factors. An obvious source of more accurate knowledge about climate change is better education. Indeed, educational attainment has long been identified as a consistent predictor of environment-related perceptions and concerns (e.g. Dietz et al. 1998), and a meta-analysis of close to 200 polls and academic studies has revealed that education is one of the strongest correlates of the belief in climate change (Hornsey et al. 2016). More recently, cognitions about the existence, origins and impacts of climate change have been found to display a strong left-right ideological divide in many countries, with adherents to the

The original article can be found online at https://doi.org/10.1007/ s13412-021-00745-7.

Heinz Welsch

welsch@uni-oldenburg.de

1 Department of Economics, University of Oldenburg, 26111 Oldenburg, Germany left expressing greater belief in and concern about climate change than adherents to the right (e.g. McCright et al. 2015, McCright et al. 2016, Hornsey et al. 2016, Hornsey et al. 2018). Indeed, political ideology and affiliation are stronger predictors of climate change belief than any other demographic variable (Hornsey et al. 2016).

The psychological mechanism behind the association between ideological identity and climate change beliefs is identity-protective cognition (Kahan et al. 2007), that is, people adjust their beliefs and world views to their personal and social identities in order to minimize cognitive dissonance (Festinger 1957). The techniques employed in forming identity-protective cognitions include individuals' differentially attending to (through selective exposure or avoidance) and/or processing (through motivated reasoning) information (e.g. Garrett et al. 2011, Kunda 1990, respectively) in a way that agrees with their values and world views. Due to identity-protective cognition, division in terms of ideological position may translate into division of climate change beliefs.

As shown by Kahan et al. (2017a), politically polarized views on science in the U.S. are better explained by identity-protecting cognitive strategies than by the competing hypothesis of deficits in the public's capacity to comprehend scientific evidence. In addition - contrary to conventional expectations - ideology-dependence of climate change cognitions has been found to be stronger rather than weaker in individuals with greater science literacy and numeracy, on the grounds that these abilities facilitate adjustment of beliefs to identity through selection and processing of information (Kahan et al. 2017a).

Considering that science literacy and numeracy may be related to general educational attainment, this finding suggests that a higher level of education may foster rather than attenuate the identity-dependence of climate change cognitions. Consistent with this view, Czarnek et al. (2020) found the ideological divide of climate change cognitions in developed countries to be increasing in individuals' years of 
education, whereas the evidence is ambiguous with respect to less developed countries.

While the bulk of the literature on identity-protective climate change cognitions focused on ideological identity (political affiliation or position on the left-right scale), one recent paper (Welsch 2021) has studied the relationship between moral identity and climate change cognitions. Drawing on so-called moral foundations theory (Haidt and Joseph 2007, Graham et al. 2011, Haidt 2012), the paper found significant relationships between beliefs which foster climate friendly behaviors and the endorsement of universalist (individual-focused) - as opposed to parochial (group-focused) - moral values. Specifically, individuals hold stronger beliefs that climate change has bad impacts the more they endorse the moral values of Fairness and Liberty (universalist values) and the less they endorse Authority and Sanctity (parochial values). Importantly, these relationships hold even when controlling for ideological identity (position on the left-right scale).

It should be noted that much of the work on ideologydependent cognition, motivated reasoning, and the moderating role of science literacy and numeracy focused on North American populations (e.g., Kahan et al. 2007, Kahan et al. 2017a). Analyzing data from 25 developed and emerging countries, Hornsey et al. (2018) found relationships between climate skepticism and 5 ideological variables to be statistically significantly stronger in the U.S. than in the pool of 24 other nations. The relationships also tended to be stronger in 5 English speaking nations (other than the U.S.) than in the 24-nation pool, but not significantly so. At the level of individual countries, the relationship between climate skepticism and more right-leaning ideology was positive in 19 out of 25 countries (significantly so in 7 countries). While there does not seem to be evidence on the moderating role of science literacy and numeracy in the cognitionideology relationship outside the U.S. (Kahan et al. 2017a), Czarnek et al. (2020) found a significant moderating role of the related notion of educational attainment in a set of 22 European countries. With respect to the relationship between climate change cognitions and moral identity, a moderating role for science literacy and numeracy or education has not been studied as yet.

The present paper studies the role for climate change cognitions of ideological identity, moral identity, and cognitive ability jointly. It augments the literature on climate change cognitions, identity, and cognitive skills and abilities in several ways. First, it extends the evidence on the ideologycognition-ability relationship (Kahan et al. 2017a) from a small U.S. sample to a large representative European sample. Second, in focusing on the morality-cognition nexus it studies a larger set of climate change cognitions than previously considered (Welsch 2021). Third, using educational attainment as a measure of cognitive ability, it studies for the first time the role of cognitive ability as a potential moderator of the morality-cognition relationship. Finally, it discusses climate policy conclusions, drawing on the notion of the "tragedy of the science communication commons" (Kahan 2017, Kahan et al. 2017b).

The empirical analysis uses about 30,000 observations for 23 European countries from Round 8 of the European Social Survey (ESS) and involves four climate change cognitions (the world climate is changing; climate change is caused by human activities; climate change has bad impacts; reducing personal-level energy use can reduce climate change), individuals' placement on the left-right scale, and individuals' endorsement of six moral foundations (Care, Fairness, Liberty, Loyalty, Authority, and Purity/Sanctity).

The original article has been updated.

Open Access This article is licensed under a Creative Commons Attribution 4.0 International License, which permits use, sharing, adaptation, distribution and reproduction in any medium or format, as long as you give appropriate credit to the original author(s) and the source, provide a link to the Creative Commons licence, and indicate if changes were made. The images or other third party material in this article are included in the article's Creative Commons licence, unless indicated otherwise in a credit line to the material. If material is not included in the article's Creative Commons licence and your intended use is not permitted by statutory regulation or exceeds the permitted use, you will need to obtain permission directly from the copyright holder. To view a copy of this licence, visit http://creativecommons.org/licenses/by/4.0/.

Publisher's note Springer Nature remains neutral with regard to jurisdictional claims in published maps and institutional affiliations. 